\title{
Representatividade da amostra de solo de acordo com o volume coletado em lavoura de café Arábica
}

\author{
André Guarçoni, Gustavo Soares de Souza, Henrique de Sá Paye
}

Instituto Capixaba de Pesquisa, Assistência Técnica e Extensão Rural - INCAPER, Vitória, ES. E-mail: guarconi@incaper.es.gov.br

\section{Resumo}

Para a determinação da fertilidade do solo, uma característica das amostras simples comumente desprezada é o seu volume, que apresenta relação com o número de amostras coletadas para formar uma amostra composta representativa. O objetivo deste trabalho foi estabelecer a influência do volume das amostras simples na estimativa da variabilidade de características químicas do solo e estimar os desvios em torno da média, na coleta de 20 amostras simples com diferentes equipamentos, em um Latossolo Vermelho-Amarelo argiloso, cultivado com café arábica. Foram coletados cinco grupos de 30 amostras simples de solo, com os respectivos volumes: $80,320,720,1.280$ e $2.000 \mathrm{~cm}^{3}$, na camada de $0-20 \mathrm{~cm}$, totalizando 150 amostras simples, nas quais foram determinados: $\mathrm{pH}, \mathrm{P}, \mathrm{K}, \mathrm{Ca}^{2+}, \mathrm{Mg}^{2+}$ e $\mathrm{Al}^{3+}$. Foram selecionados modelos que explicassem a variação dos teores em função do volume das amostras de solo. Foram calculados os desvios tolerados em torno da média utilizando três equipamentos: trado, sonda e enxadão. O aumento no volume de solo coletado reduziu a variabilidade das características e, consequentemente, o número de amostras simples necessárias para formar uma amostra composta. 0 enxadão mostrou-se o equipamento de coleta mais eficiente, uma vez que proporciona maior representatividade da amostra composta formada.

Palavras-chave: amostragem; fertilidade do solo; amostras simples; variabilidade.

\section{Soil sample representativy according to the volume collected in Arabica coffee}

\begin{abstract}
For the determination of soil fertility, a characteristic of the commonly overlooked samples is their volume, which is related to the number of samples collected to form a representative composite sample. The objective of this work was to establish the influence of the volume of the simple samples in the estimation of the variability of chemical characteristics of the soil and to estimate the deviations around the average tolerated in the collection of 20 simple samples with different equipments in a clay Red-Yellow Latosol cultivated with arabica coffee. Five groups of 30 simple soil samples were collected, with the respective volumes: $80,320,720,1,280$ and $2,000 \mathrm{~cm}^{3}$, in the $0-20 \mathrm{~cm}$ layer, totaling 150 simple samples. In these samples $\mathrm{pH}, \mathrm{P}, \mathrm{K}, \mathrm{Ca}^{2+}, \mathrm{Mg}^{2+}$ and $\mathrm{Al}^{3+}$ were determined. Models were selected that explained the variation of the contents as a function of the volume of the soil samples. Mean deviations around the mean were also calculated using three equipments: soil, probe and hoe. The increase in the volume of soil collected reduced the variability of the characteristics and consequently the number of simple samples needed to form a composite sample. The hoeing was the most efficient collection equipment, since it would provide greater representativeness of the formed composite sample.
\end{abstract}

Keywords: sampling; soil fertility; single samples; variability. 


\section{Introdução}

Dentro do processo produtivo do café ou de qualquer cultura, uma etapa de extrema relevância é a recomendação de corretivos e fertilizantes. Para que as recomendações atinjam seu objetivo, deve-se conhecer a fertilidade do solo no qual será ou está implantada a cultura. Nesse caso, de acordo com Mallarino (1996) e Prezotti e Guarçoni (2013), um importante erro potencial, envolvido na avaliação da fertilidade do solo, pode ser gerado pela amostragem inadequada.

Uma amostragem representativa é aquela que melhor caracteriza uma área de interesse, realizada por meio da coleta de um número de pontos que alia precisão na estimativa e minimiza o esforço (SANTOS et al., 2017). Assim, para que a amostragem seja eficiente e econômica, deve-se trabalhar com amostras simples e compostas de solo. As amostras simples são aquelas coletadas de forma individual, em pontos escolhidos ao acaso, dentro de cada unidade de amostragem (talhão homogêneo) da lavoura (RAIJ, 2017). Já as amostras compostas são formadas pela mistura homogênea de um número predefinido de amostras simples de pequeno volume (CLINE, 1944).

Há três fatores distintos envolvidos na amostragem de solo para determinação adequada de uma característica química particular: número de amostras a ser coletado, local de coleta e volume da amostra (UPCHURCH; EDMONDS, 1991). Para amostragem de solo na cultura do café, geralmente são coletadas, ao acaso, 20 amostras simples de solo sob a copa de cafeeiros distribuídos na unidade de amostragem, visando formar uma amostra composta representativa (GUARÇONI, 2016). Nesse caso, os dois primeiros fatores descritos por Upchurch e Edmonds (1991) já estariam contemplados. Entretanto, Guarçoni et al. (2007) observaram que o volume da amostra simples tem elevada influência na estimativa da variabilidade de características químicas relacionadas à fertilidade do solo, sendo os teores de fósforo $(\mathrm{P})$ e potássio $(\mathrm{K})$ os que apresentaram maior variação.

$\mathrm{Na}$ cultura do café, pouca atenção tem sido dada ao volume das amostras simples coletadas, sendo preferido para amostragem o equipamento denominado sonda, o qual apresenta um diâmetro de entrada geralmente de $1,70 \mathrm{~cm}$, o que geraria amostras simples de aproximadamente $45,4 \mathrm{~cm}^{3}$, considerando uma amostragem de solo de 0 a $20 \mathrm{~cm}$ de profundidade. Nessa situaçã̃o, devido ao reduzido volume coletado, os resultados obtidos por meio da análise de solo podem não representar corretamente a fertilidade média da área amostrada (GUARÇONI et al., 2007). Esse fato pode comprometer a eficácia dos programas de adubação e o processo produtivo.

O presente trabalho teve como objetivo estabelecer a influência do volume das amostras simples na estimativa da variabilidade de características químicas do solo, determinar o número de amostras simples necessário para formar uma amostra composta representativa, de acordo com o volume de solo utilizado na amostragem, e estimar os desvios a serem tolerados em torno da média, ao se coletar conjuntos de 20 amostras simples de solo com diferentes equipamentos de amostragem, em um Latossolo Vermelho-Amarelo argiloso, cultivado com café arábica.

\section{Material e Métodos}

$O$ estudo foi realizado em um Latossolo Vermelho-Amarelo argiloso, cultivado com café arábica (Coffea arabica L.) por nove anos (2007 a 2015), na Região Serrana do estado do Espírito Santo ( $20^{\circ} 22^{\prime} 08.2^{\prime \prime} \mathrm{S} 41^{\circ} 03^{\prime} 45.0^{\prime \prime} \mathrm{W}$; com média de $18{ }^{\circ} \mathrm{C}$ e $1.250 \mathrm{~mm}$ anuais de precipitação). A lavoura de café recebia, anualmente, adubação sob a copa das plantas, de acordo com a análise de solo.

Numa unidade de amostragem individualizada na lavoura (talhão homogêneo, de acordo com Cantarutti et al., 2007), sob a copa das plantas, no mês de maio, foram coletados cinco grupos de amostras, formados por 30 amostras simples de solo cada, com os respectivos volumes: $80,320,720,1.280$ e 2.000 $\mathrm{cm}^{3}$, correspondendo a prismas de $2 \times 2,4 \times 4,6 \times$ $6,8 \times 8$ e $10 \times 10 \mathrm{~cm}$ de lado por $20 \mathrm{~cm}$ de profundidade, totalizando 150 amostras simples. Para coleta das amostras simples de solo foram utilizadas lâminas galvanizadas com $1 \mathrm{~mm}$ de espessura, com $20 \mathrm{~cm}$ de altura e largura correspondente à seção $(2,4,6,8$ ou $10 \mathrm{~cm})$.

As amostras simples de solo coletadas foram secas ao ar, peneiradas (2 mm) (TFSA), homogeneizadas e analisadas, sendo determinados o $\mathrm{pH}$ em água (2:1), os teores de $\mathrm{P}$ e $\mathrm{K}$ disponíveis (Mehlich-1), os teores de $\mathrm{Ca}^{2+}$, $\mathrm{Mg}^{2+}$ e $^{3 l^{3+}}\left(\mathrm{KCl} 1 \mathrm{~mol} \mathrm{~L}^{-1}\right)$ (DONAGEMA et al., 2011). 
Foram determinadas as médias $(\hat{Y})$ das características químicas avaliadas, bem como os valores dos respectivos desvios-padrão (s) e coeficientes de variação (CV), para cada um dos cinco grupos de amostras. Utilizando análise de regressão, foram selecionados os modelos que melhor explicaram o comportamento das estimativas da variabilidade (CV) das características químicas do solo, em função do volume das amostras simples utilizadas na amostragem.

O número de amostras simples, necessário para formar uma amostra composta, e a variação em torno da média (f) a ser aceita, para a coleta de 20 amostras simples, foram calculados por meio da fórmula proposta por Cline (1944):

$\mathrm{n}=(\mathrm{t} \alpha / 2 \mathrm{CV} / \mathrm{f})^{2}$

em que: $t \alpha / 2$ é o valor tabelado da distribuição $t$ de Student, igual a 2,045 (referente a $5 \%$ de probabilidade e n-1 = 29); CV é o coeficiente de variação; e f é o desvio aceito em torno da média, no primeiro caso igual a $20 \%$.

Utilizando as equações de regressão dos coeficientes de variação, em função dos volumes das amostras simples de solo, foram calculados, para três diferentes equipamentos de coleta (sonda, trado e enxadão), os números de amostras que melhor representariam as características de maior variabilidade, bem como a tolerância de variação em torno da média a ser aceita se fossem coletadas 20 amostras simples de solo para cada equipamento.

\section{Resultados e Discussão}

Cada volume utilizado na amostragem de solo gerou médias similares para as características químicas do solo estudadas (Tabela 1). Entretanto, isso se deve ao acaso, uma vez que a estimativa da variabilidade da maioria das características químicas, medida pelo coeficiente de variação, foi elevada (>30\%), especialmente para $\mathrm{P}$ (Tabela 1). Dessa forma, as médias dos teores revelados pelas análises das amostras de solo poderiam ser extremamente discrepantes, caso as amostras simples fossem retiradas em locais de maior ou menor concentração. Schlindwein e Anghinoni (2002) e Guarçoni et al. (2007) também observaram maior variabilidade dos teores de $P$ em relação aos demais nutrientes avaliados, mas em áreas com plantio direto ou convencional de culturas anuais. Em lavoura de café arábica, Ferraz et al. (2012) observaram variabilidades de $\mathrm{P}$ compatíveis com as detectadas neste estudo, demonstrando que o manejo utilizado nas lavouras de café pode gerar elevada variabilidade de teores de determinados nutrientes no solo.

Em termos médios, a variabilidade das características químicas avaliadas, medida pelo coeficiente de variação, seguiu a seguinte ordem crescente de magnitude: $\mathrm{pH}<\mathrm{K}<\mathrm{Mg}^{2+}<\mathrm{Ca}^{2+}<$ $\mathrm{Al}^{3+}<\mathrm{P}$ (Tabela 1). Essa ordem é similar à observada por Alvarez e Guarçoni (2003), quando utilizaram a pá de corte para coleta de solo em sistema plantio direto. 
Tabela 1. Médias $(\hat{Y})$, desvio padrão $(s)$, coeficientes de variação $(C V)$ e equação de regressão $(C V \times V)$ de características químicas de solo cultivado com café, de acordo com o volume (V) das amostras simples coletadas

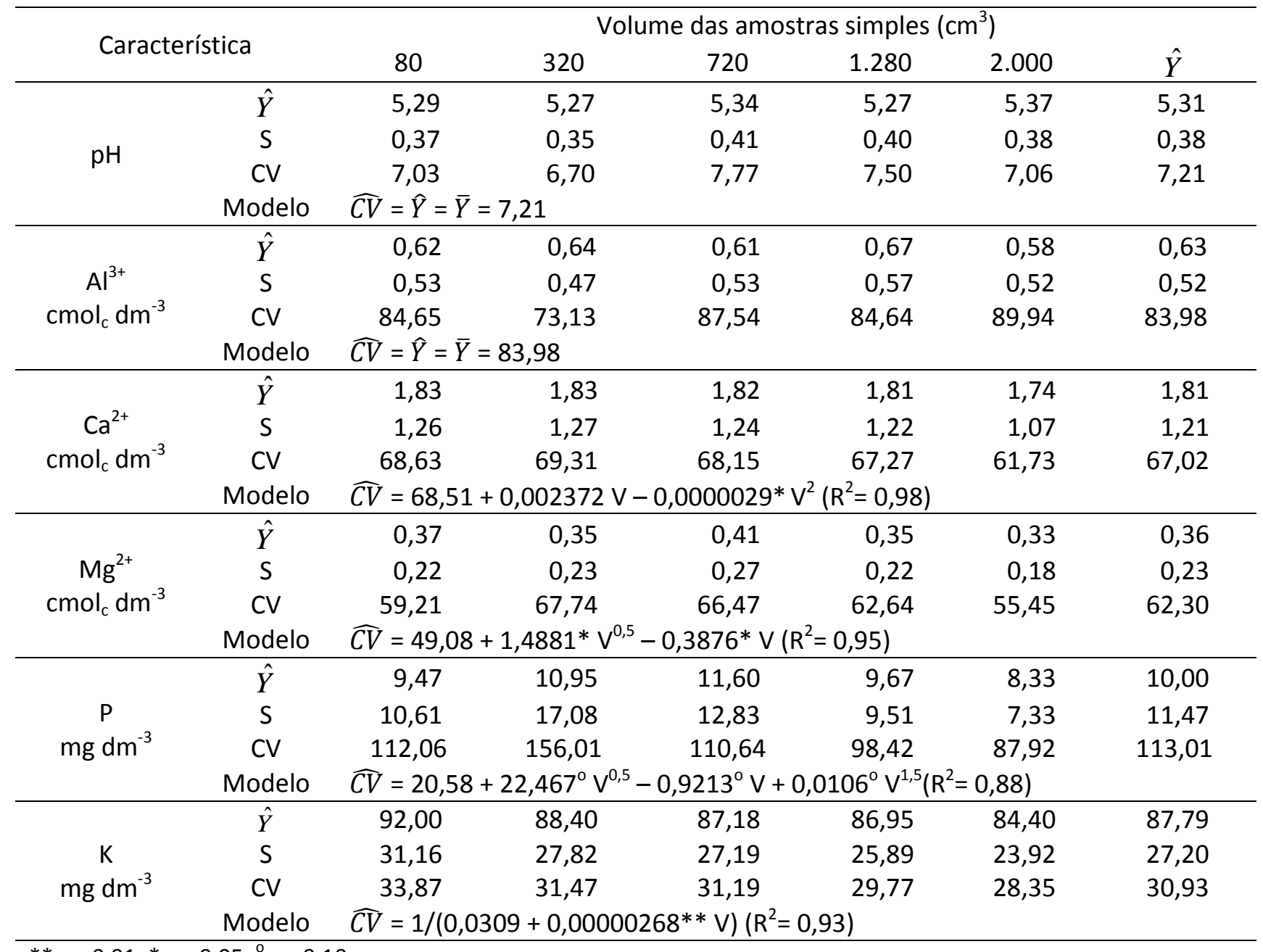

$* *: p<0,01, *: p<0,05,^{\circ}: p<0,10$.

Foram definidos modelos que explicassem a variabilidade (CV) das características químicas avaliadas em função do volume das amostras simples coletadas (Tabela 1). Não foi possível selecionar modelos para os valores de $\mathrm{pH}$ e os teores de $\mathrm{Al}^{3+}$, sendo estes representados pela média dos CV. Para os teores de $\mathrm{Ca}^{2+}, \mathrm{Mg}^{2+}$ e $\mathrm{P}$ foram selecionados os modelos quadráticos, raíz-quadrático e cúbico-raiz, respectivamente (Tabela 1 ). A escolha dos modelos demonstra que a variabilidade das características foi relativamente baixa para volumes de amostra reduzidos $\left(80 \mathrm{~cm}^{3}\right)$, aumentando com o volume da amostra simples, e reduzindo a patamares inferiores aos iniciais, quando o volume das amostras simples foi de $2.000 \mathrm{~cm}^{3}$.

O comportamento apresentado pelos teores de $\mathrm{Ca}^{2+}, \mathrm{Mg}^{2+}$ e $\mathrm{P}$ não era esperado. Como reportam Schlindwein e Anghinoni (2002) e Guarçoni et al. (2007), a variabilidade de características químicas do solo deveria ser elevada para menores volumes de amostras simples, sendo reduzida à medida em que os volumes das amostras simples fossem aumentados. Mas, no presente trabalho, foi observada, para a maioria das características em que foi possível selecionar um modelo de resposta, variabilidade baixa nas amostras simples com volume de $80 \mathrm{~cm}^{3}$, em relação às amostras simples de $320 \mathrm{~cm}^{3}$ (Tabela 1), seguindo, a partir deste último volume, a lógica apresentada pelos autores citados.

No trabalho de Schlindwein e Anghinoni (2002), o sistema plantio direto, no qual coletaram amostras de solo, já estava bem desenvolvido, sendo o efeito de sulcos de plantio na amostragem pouco pronunciado, gerando maior variabilidade para amostras simples de menor volume, sendo a mesma reduzida à medida em que se aumentou o volume das amostras simples. Já no trabalho de Guarçoni et 
al. (2007), esse mesmo tipo de resposta ocorreu apenas na situação em que as amostras de solo foram coletadas após a aração e a gradagem do terreno, ou seja, quando a distribuição superficial de teores no solo era mais homogênea. Para as situações de plantio direto ainda não consolidado e plantio convencional antes da aração e da gradagem (manutenção de sulcos de plantio), esses autores observaram a mesma resposta do presente trabalho, obtida na maioria das características químicas para as quais foi possível selecionar modelos, sendo baixa variabilidade para as amostras simples de pequeno volume, seguida de aumento da variabilidade à medida em que se elevaram os volumes das amostras e posterior redução na variabilidade (Tabela 1). Os autores citados explicam a resposta como consequência dos sulcos de plantio, presentes tanto no plantio direto ainda não consolidado quanto no plantio convencional antes da aração e da gradagem, o que geraria uma dependência espacial cíclica, e interferiria diretamente na forma de resposta esperada.

A maior variabilidade de teores, no menor volume coletado, com posterior redução na variabilidade à medida em que foram aumentados os volumes utilizados na amostragem, foi observada no presente estudo para o K, tendo sido selecionado o modelo hiperbólico (Tabela 1). A mesma tendência foi observada por Guarçoni et al. (2007) no plantio convencional após a aração, quando os teores de nutrientes na camada superficial do solo são horizontalmente mais homogêneos, como consequência direta da aração e da gradagem, fato já relatado por Vasconcelos et al. (1982).

A partir dessas observações é possível inferir que o manejo da adubação sob a copa de cafeeiros pode gerar uma variabilidade de teores de nutrientes tão elevados quanto o sistema plantio direto inconsolidado e quanto o plantio convencional antes da aração e da gradagem. Prova disso é que os CV de $\mathrm{P}$ e $\mathrm{K}$ obtidos no presente trabalho são iguais ou até maiores do que os encontrados em trabalhos com plantio direto, como os de Alvarez e Guarçoni (2003), Guarçoni et al. (2006 e 2007), Zanão Júnior et al. (2010), Cherubin et al. (2014) e Dias et al. (2015), e bem maiores do que os reportados por Guarçoni et al. (2007) para o plantio convencional após a aração.

A distribuição particionada de teores no solo pode ser devida à aplicação desuniforme de adubo fosfatado, que também é fonte de $\mathrm{Ca}$, gerando verdadeiros gradientes sob a copa das plantas. Por outro lado, a maior homogeneidade nos teores de $\mathrm{K}$, em relação à $\mathrm{P}$ e $\mathrm{Ca}^{2+}$, pode estar ligada ao bem conhecido carreamento deste nutriente das folhas do café, via água de chuva ou irrigação por aspersão, com posterior deposição mais homogênea no solo, dada a conformidade da copa desta espécie vegetal. Costa et al. (2009) encontraram efeito completamente diverso no milho, uma vez que o carreamento de $\mathrm{K}$ das folhas, via água de chuva, gerou gradientes de concentração no solo. Essa diferença pode ser explicada pela forma em que estão distribuídas as folhas do milho, que tendem a depositar o $\mathrm{K}$ no solo próximo ao colmo ou mais distante, onde ocorre a curvatura das mesmas.

Como visto, o aumento do volume da amostra simples de solo, a partir de $320 \mathrm{~cm}^{3}$, causou redução na estimativa da variabilidade das características químicas avaliadas, mas amostras simples de solo de pequeno volume também apresentaram variabilidade reduzida. Amostras de volume intermediário foram as que apresentaram maior variabilidade (Tabela 1). Entretanto, a utilização de volumes próximos de $80 \mathrm{~cm}^{3}$ para a amostragem pode não ser adequada, uma vez que o valor médio pode variar muito em função do local em que se coleta a amostra simples de solo (local de maior ou menor concentração de nutrientes), dado o pequeno espaço lateral amostrado. As amostras coletadas, neste caso, teriam sua dimensão lateral menor do que as microvariações do solo (< $5 \mathrm{~cm}$ ), segundo classificação de James e Wells (1990), tendendo a sofrer influência de variações a curtas distâncias no solo, o que pode afetar a detecção de concentrações de elementos químicos.

A partir disso, optou-se por seguir a sugestão de Guarçoni et al. (2007) para o caso de amostras de menor volume apresentarem reduzida variabilidade, causada provavelmente por uma baixa ou elevada detecção de maiores concentrações de nutrientes. Assim, foram retiradas as amostras de $80 \mathrm{~cm}^{3}$ para a definição de modelos que representassem a variabilidade (CV) dos teores $\mathrm{Ca}^{2+}, \mathrm{Mg}^{2+}$ e $\mathrm{P}$, mantendo-se as amostras de $80 \mathrm{~cm}^{3}$ no caso do K. Nesse caso, o efeito do volume das amostras simples de solo sobre a variabilidade de características químicas seguiu o modelo já observado por Schlindwein e Anghinoni (2002) e Guarçoni et al. (2007), ou seja, redução na variabilidade à medida em que se aumentou o volume das amostras simples de 
solo (Figura 1). McBratney e Webster (1983), Webster e Burgess (1984) e Burrough (1991) também observaram redução na estimativa da variabilidade de características químicas do solo, quando aumentaram, porém, o número de amostras simples. Portanto, há duas alternativas para se reduzir a estimativa da variabilidade de características químicas do solo: aumentar o número de amostras simples ou aumentar o volume das amostras simples coletadas para se formar uma amostra composta representativa.

A redução na estimativa da variabilidade da maioria das características químicas avaliadas, quando se aumentou o volume das amostras simples, deveu-se à expansão na área das amostras simples. Essa expansão lateral incorpora no volume de solo coletado as variações horizontais a curtas distâncias, ou seja, as microvariações (< 5 cm) (JAMES; WELLS, 1990), as quais, segundo Guarçoni et al. (2007), apresentam elevada influência sobre a estimativa da variabilidade de características químicas do solo.

Figura 1. Coeficientes de variação (CV) de tores $\mathrm{Ca}^{2+}, \mathrm{Mg}^{2+}, \mathrm{P}$ e K em solo cultivado com café, de acordo com o volume da amostra simples coletada. ${ }^{* *}: p<0,01 e^{*}: p<0,05$.
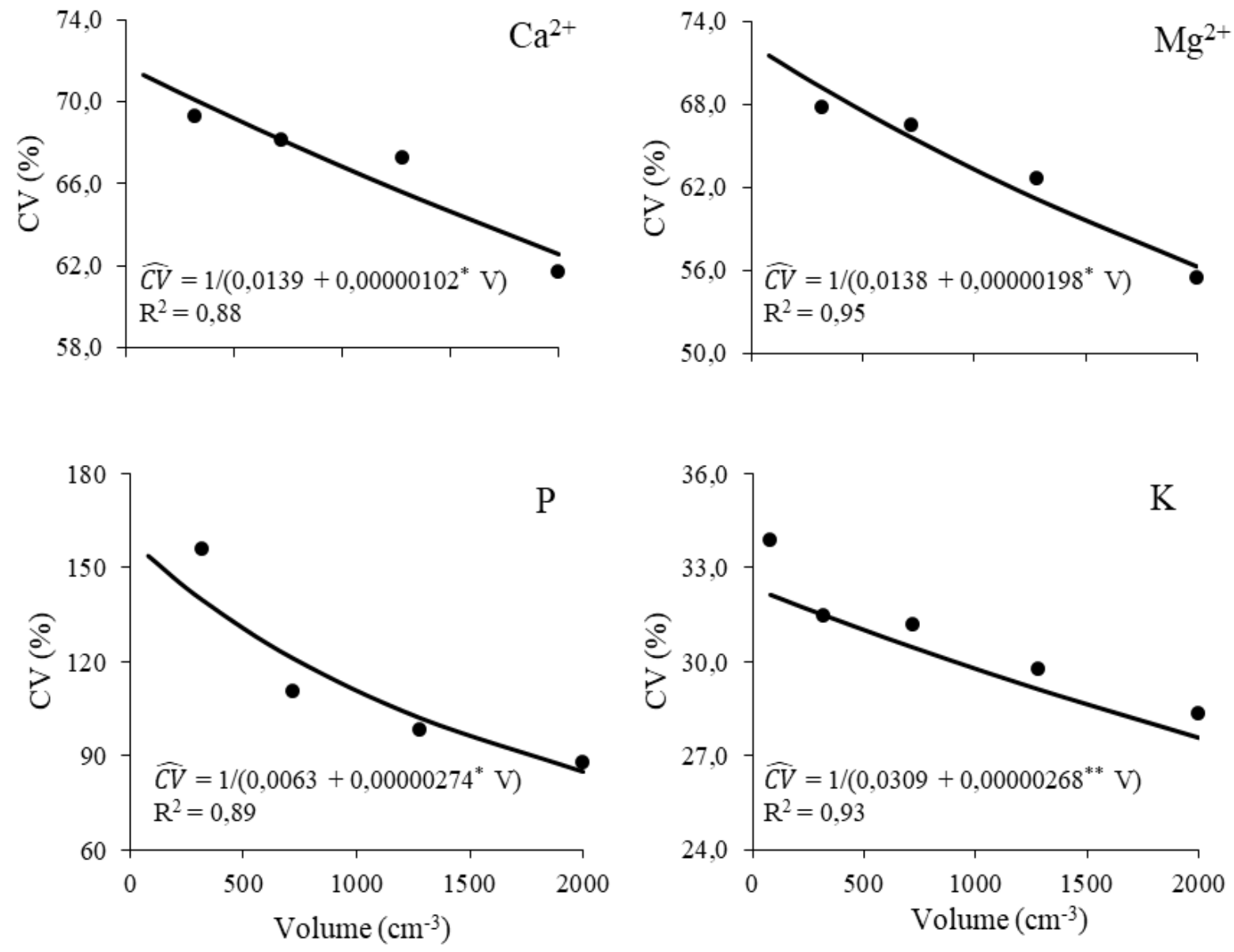

O número de amostras simples necessário para representar adequadamente os teores médios de $\mathrm{Al}^{3+}, \mathrm{Ca}^{2+}, \mathrm{Mg}^{2+}$ e $\mathrm{P}$, aceitandose um desvio em torno da média de $20 \%$ ( $f=$ $20 \%)$, ficou acima de 20, comumente recomendadas para esta situação (GUARÇONI, 2016), atingindo números extremos para o nutriente $P$ (Tabela 2). O número de pontos amostrais para formar uma amostra composta é condicionado pelo nível de precisão desejado (ROZANE et al., 2011). Dessa forma, a definição de um mesmo número de amostras simples vai resultar em variações distintas na precisão para as diferentes características químicas do solo, a 
depender da variabilidade intrínseca de cada uma delas.

A elevada variabilidade de $P$ (Figura 1) gerou um número impraticável de amostras simples para formar uma amostra composta representativa da unidade de amostragem, mesmo quando se aumentou o volume das amostras simples e se aceitou um desvio em torno da média de $20 \%$ (Tabela 2). Outro fato importante é que a amostragem de solo não é realizada separadamente para cada característica química, assim, a precisão final obtida após o processo de amostragem dependerá das características do solo analisadas, concordando com Santos et al. (2017) e Rozane et al. (2011).

Tabela 2. Número de amostras simples de solo ${ }^{1 /}$ necessárias para formar uma amostra composta representativa de características químicas de solo cultivado com café, de acordo com o volume das amostras simples coletadas

\begin{tabular}{lcrcccc}
\hline & \multirow{2}{*}{ Característica $^{2 /}$} & \multicolumn{5}{c}{ Volume das amostras simples de solo $\left(\mathrm{cm}^{3}\right)$} \\
\cline { 3 - 7 } & - & 1 & 320 & 720 & 1.280 & 2.000 \\
\hline $\mathrm{pH}$ & $\left(\mathrm{cmol}_{\mathrm{c}} \mathrm{dm}^{-3}\right)$ & 75 & 56 & 1 & 1 & 1 \\
$\mathrm{Al}^{3+}$ & $\left(\mathrm{cmol}_{\mathrm{c}} \mathrm{dm}^{-3}\right)$ & 53 & 51 & 49 & 75 & 85 \\
$\mathrm{Ca}^{2+}$ & $\left(\mathrm{cmol}_{\mathrm{c}} \mathrm{dm}^{-3}\right)$ & 54 & 50 & 45 & 45 & 41 \\
$\mathrm{Mg}^{2+}$ & $\left(\mathrm{mg} \mathrm{dm}^{-3}\right)$ & 247 & 204 & 153 & 109 & 33 \\
$\mathrm{P}$ & $\left(\mathrm{mg} \mathrm{dm}^{-3}\right)$ & 11 & 10 & 10 & 9 & 75 \\
$\mathrm{~K}$ & & &
\end{tabular}

$1 / \mathrm{n}=(\mathrm{t} \alpha / 2 \mathrm{CV} / \mathrm{f})^{2} ;{ }^{2 /} \mathrm{pH}$ e $\mathrm{Al}^{3+}$ : número de amostras calculado conforme Cline (1944); $\mathrm{Ca}^{2+}, \mathrm{Mg}^{2+}, \mathrm{P}$ e K: número de amostras calculado a partir dos valores de CV estimados pelas equações de regressão selecionadas.

O aumento do volume das amostras simples reduziu significativamente o número de amostras a serem coletadas, mesmo que no maior volume este número tenha permanecido elevado. 0 aumento do volume de 80 para 2.000 $\mathrm{cm}^{3}$ reduziu o número de amostras simples em $22,6 \%$ para $\circ \mathrm{Ca}^{2+}$, em 38,9\% para o $\mathrm{Mg}$ e em $69,3 \%$ para o $\mathrm{P}$ (Tabela 2 ).

$O$ nutriente $P$, devido à reduzida mobilidade nos solos (NOVAIS; SMITH, 1999; FINK et al., 2014), apresenta elevada variabilidade, o que acarreta a necessidade de um elevado número de amostras simples para sua adequada representação. A tendência de que amostras simples de maior volume gerem menor variabilidade e, consequentemente, menor número de amostras simples se confirmou para o $P$ e para os outros nutrientes de menor mobilidade no solo (Tabelas 1, 2 e 3), fato que corrobora os resultados de Schlindwein e Anghinoni (2002) e Guarçoni et al. (2007).

Considerando que mesmo elevando-se o volume da amostra simples, o número de amostras a ser coletado foi ainda superior a 20, para os nutrientes de maior variabilidade no solo (Tabelas 2 e 3), estimou-se qual o desvio em torno da média deve ser tolerado ( $f$ ) quando se coletam 20 amostras simples de solo com a sonda, com o trado de caneca ou com o enxadão. Com a utilização da sonda e do trado, os desvios em torno da média a serem tolerados são de

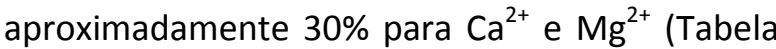
$3)$, o que não deixa de ser uma variação aceitável. Contudo, para o $\mathrm{P}$, deve-se aceitar um desvio de $70 \%$ para a sonda e de $61 \%$ para o trado. Já para o enxadão, o desvio foi de $39 \%$ (Tabela 3). 
Tabela 3. Número de amostras simples de solo (№) necessário para representar adequadamente os teores médios de $\mathrm{Ca}^{2+}, \mathrm{Mg}^{2+}, \mathrm{P}$ e K $(\mathrm{f}=20 \%$ ), bem como os desvios em torno da média ( $\mathrm{f} \%$ ) a serem tolerados na amostragem do solo quando forem coletadas 20 amostras simples $(20 \mathrm{~cm}$ de profundidade) com três equipamentos em lavoura de café.

\begin{tabular}{|c|c|c|c|}
\hline \multirow[b]{2}{*}{ Variável } & \multicolumn{3}{|c|}{ Equipamento $^{1 /}$} \\
\hline & $\begin{array}{c}\text { Sonda } \\
(\varnothing=2,3 \mathrm{~cm})\end{array}$ & $\begin{array}{c}\text { Trado } \\
(\varnothing=5,4 \mathrm{~cm})\end{array}$ & $\begin{array}{c}\text { Enxadão } \\
\text { (Fatia de } 20 \times 5 \mathrm{~cm})\end{array}$ \\
\hline & \multicolumn{3}{|c|}{$\mathrm{Ca}^{2+}$} \\
\hline № & 53 & 50 & 41 \\
\hline$f \%$ & 32,60 & 31,74 & 28,62 \\
\hline & \multicolumn{3}{|c|}{$\mathrm{Mg}^{2+}$} \\
\hline № & 53 & 48 & 33 \\
\hline$f \%$ & 32,70 & 31,06 & 25,74 \\
\hline & \multicolumn{3}{|c|}{$\mathrm{P}$} \\
\hline № & 247 & 184 & 75 \\
\hline$f \%$ & 70,23 & 60,65 & 38,85 \\
\hline & \multicolumn{3}{|c|}{$\mathrm{K}$} \\
\hline № & 11 & 10 & 8 \\
\hline$f \%$ & 14,69 & 14,23 & 12,61 \\
\hline
\end{tabular}

Para a coleta de amostras de solo visando a avaliação da fertilidade em lavouras de café, o enxadão, que pode ser substituído pela pá de corte, é o equipamento que gera amostras compostas mais representativas da unidade de amostragem (talhão homogêneo). O enxadão, devido ao material com o qual é comumente fabricado, pode, segundo a crença corrente, contaminar a amostra, gerando incertezas na análise de micronutrientes. Entretanto, considerando as fontes de variação envolvidas na análise de micronutrientes, o benefício gerado pela maior representatividade da amostra retirada com enxadão torna a possível contaminação algo insignificante.

A sonda pode ser utilizada para a coleta de amostras, especialmente por sua facilidade de uso, mas deve-se assumir a reduzida representatividade dos teores de P. Entretanto, esta baixa representatividade é comum aos diversos equipamentos que podem ser utilizados. Para a coleta de amostras representativas dos teores de $\mathrm{P}$, o volume ou o número de amostras simples a ser coletado seria muito elevado, tornando a amostragem de solo impraticável. O mais coerente é assumir um desvio em torno da média aceitável, recomendando os fertilizantes fosfatados de forma criteriosa e sempre com embasamento da análise foliar, além da análise de solo.

É importante ressaltar que, para cada forma e volume das amostras simples utilizadas na amostragem prévia, existirá um número ótimo de amostras simples a ser coletado, o qual irá conferir a mesma representatividade à amostra composta formada. Muitas vezes, a coleta de um maior número de amostras simples de pequeno volume gera um menor esforço de amostragem do que a coleta de um reduzido número de amostras simples de volume elevado (GUARÇONI et al., 2007), mas não se deve desprezar a maior representatividade gerada por amostras de solo de maior volume, quando se coleta 20 amostras para representar a fertilidade média de um talhão.

\section{Conclusões}

1- O manejo da adubação em lavouras de café gera variabilidade de características químicas do solo compatível à observada em plantio direto inconsolidado ou plantio convencional antes da aração.

2- O aumento no volume de solo coletado reduziu a variabilidade das características químicas e o número de amostras simples necessário para formar uma amostra composta.

3- O enxadão mostrou-se o equipamento de coleta mais eficiente e proporcionou maior representatividade da amostra composta. 


\section{Referências}

ALVAREZ, V., V.H.; GUARÇONI, A. Variabilidade horizontal da fertilidade do solo de uma unidade de amostragem em sistema plantio direto. Revista Brasileira de Ciência do Solo, Viçosa, v.27, n.2, p.297-310, 2003. https://doi.org/10.1590/S010006832003000200010

BURROUGH, P.A. Sampling designs for quantifying map unit composition. In: MUSBACH, M.J.; WILDING, L.P. (Eds.). Spatial variabilities of soil and landforms. Madison: Soil Science Society of America, 1991. p.89-125.

CANTARUTTI, R.B.; BARROS, N.F.; MARTINEZ, H.E.P.; NOVAIS, R.F. Avaliação da fertilidade do solo e recomendação de fertilizantes. In: NOVAIS, R.F.; ALVAREZ V., V.H.; BARROS, N.F.; FONTES, R.L.; CANTARUTTI, R.B.; NEVES, J.C.L. (Eds.). Fertilidade do solo. Viçosa-MG: Sociedade Brasileira de Ciência do Solo, 2007. Cap. XIII. p. 769-850.

CHERUBIN, M. R.; SANTI, A. L.; EITELWEIN, M. T.; MENEGOL, D. R.; DA ROS, C. O.; PIAS, O. H. C.; BERGHETTI, J. Eficiência de malhas amostrais utilizadas na caracterização da variabilidade espacial de fósforo e potássio. Ciência Rural, Santa Maria, v.44, n.3, p.425-43, 2014. https://doi.org/10.1590/S0103-

84782014000300007

CLINE, M.G. Principles of soil sampling. Soil Science, v.58, n.4, p.275-288, 1944. https://doi.org/10.1097/00010694-19441000000003

COSTA, S.E.V.G.A; SOUZA, E.D.; ANGHINONI, I.; FLORES, J.P.C.; ANDRIGUETTI, M.H. Distribuição de potássio e de raízes no solo e crescimento de milho em sistemas de manejo do solo e da adubação em longo prazo. Revista Brasileira de Ciência do Solo, Viçosa, v.33, n.5, p.12911301, 2009. $\quad$ https://doi.org/10.1590/S0100$\underline{06832009000500022}$

DIAS, M.J.; ALVES, S.M.F.; REIS, E.F.; OLIVEIRA, D.G. Probabilidade de ocorrência dos atributos químicos em um latossolo sob plantio direto. Revista Caatinga, Mossoró, v.28, n.4, p.181-189, 2015.

https://doi.org/10.1590/1983-
DONAGEMA, G.K. et al. Manual de métodos de análise de solo. 2. ed. rev. Rio de Janeiro: Embrapa Solos, 2011. 225p.

FERRAZ, G.A.E.S.; SILVA, F.M.; CARVALHO, L.C.C.; ALVES, M.C.; FRANCO, B.C. Variabilidade espacial e temporal do fósforo, potássio e da produtividade de uma lavoura cafeeira. Engenharia Agrícola, Jaboticabal, v.32, n.1, p.140-150, 2012. https://doi.org/10.1590/s0100$\underline{69162012000100015}$

FINK, J.R.; INDA, A.V.; BAYER, C.; TORRENT, J.; BARRÓN, V. Mineralogy and phosphorus adsorption in soils of south and central-west Brazil under conventional and no-tillage systems. Acta Scientiarum Agronomy, Maringá, v.36, n.3, 2014.

https://doi.org/10.4025/actasciagron.v36i3.1793 $\underline{7}$

GUARÇONI, A. Reflexões sobre nutrição e adubação do cafeeiro. Curitiba: Prismas, 2016. $167 p$.

GUARÇONI, A.; ALVAREZ V., V.H.; NOVAIS, R.F.; CANTARUTTI, R.B.; LEITE, H.G.; FREIRE, F.M. Diâmetro de trado necessário à coleta de amostras num cambissolo sob plantio direto ou sob plantio convencional antes ou depois da aração. Revista Brasileira de Ciência do Solo, Viçosa, v.31, n.5, p.947-959, 2007. https://doi.org/10.1590/S010006832007000500012

GUARÇONI, A.; ALVAREZ V., V.H.; NOVAIS, R.F.; CANTARUTTI, R.B.; LEITE, H.G.; FREIRE, F.M. Definição da dimensão do indivíduo solo e determinação do número de amostras simples necessário à sua representação. Revista Brasileira de Ciência do Solo, Viçosa, v.30, p.943954, 2006. https://doi.org/10.1590/s010006832006000600004

JAMES, D.W.; WELLS, K.L. Soil sample collection and handling: technique based on source and degree of field variability. In: Westerman, R. L. (ed.). Soil testing and plant analysis. Madison: Soil Science Society of America, 1990. p.25-44. 
MALLARINO, A.P. Spatial variability patterns of phosphorus and potassium in no-tilled for two sampling scales. Soil Science Society of America Journal, Madison, v.60, n.5, p.1473-1481, 1996. https://doi.org/10.2136/sssaj1996.03615995006 $\underline{000050027 x}$

MCBRATNEY, A.B.; WEBSTER, R. How many observations are needed for regional estimation of soil properties? Soil Science, Baltimore, v.135, p.177-183, 1983. https://doi.org/10.1097/00010694-198303000$\underline{00007}$

NOVAIS, R.F.; SMYTH, T.J. Fósforo em solo e planta em condições tropicais. Viçosa: UFV-DPS, 1999. 399p.

PREZOTTI, L.C.; GUARÇONI, A.G. Guia de interpretação de análise de solo e foliar. VitóriaES: Incaper, 2013. 104 p.

RAIJ, B. Fertilidade do solo e manejo de nutrientes. Piracicaba: International Plant Nutrition Institute, 2017. 420 p.

ROZANE, D.E.; ROMUALDO, L.M.; CENTURION, J.F.; BARBOSA, J.C. Dimensionamento do número de amostras para avaliação da fertilidade do solo. Semina: Ciências Agrárias, Londrina, v.32, n.1, p.111-118, 2011. https://doi.org/10.5433/16790359.2011v32n1p111

SANTOS, E.O.J.; GONTIJO, I.; SILVA, M.B.; PARTELLI, F.L. Sampling Design of Soil Physical Properties in a Conilon Coffee Field. Revista Brasileira de Ciência do Solo, Viçosa, v.41, n., 2017.

https://doi.org/10.1590/18069657rbcs20160426

SCHLINDWEIN, J.A.; ANGHINONI, I. Variabilidade horizontal de atributos de fertilidade e amostragem do solo no sistema plantio direto. Revista Brasileira de Ciência do Solo, Viçosa, v.24, n.1, p.85-91, 2002. https://doi.org/10.1590/S010006832000000100011

UPCHURCH, D.R.; EDMONDS, W.J. Statistical procedures for specific objectives. In: MUSBACH, M.J.; WILDING, L.P. eds. Spatial variabilities of soil and landforms. Madison: Soil Science Society of America, 1991. p.49-71.
WEBSTER, R.; BURGESS, T.M. Sampling and bulking strategies for estimating soil properties in small regions. Journal of Soil Science, Oxford, v.35, p.127-140, 1984.

https://doi.org/10.1111/i.13652389.1984.tb00267.x

ZANÃO JÚNIOR, L.A. et al. Variabilidade espacial dos teores de macronutrientes em latossolos sob sistema plantio direto. Revista Brasileira de Ciência do Solo, Viçosa, v.34, n.2, p.389-400, 2010. https://doi.org/10.1590/S010006832010000200012 